\title{
Natural humoral immune response to ribosomal P0 protein in colorectal cancer patients
}

\author{
Monica Benvenuto ${ }^{1}$, Pierpaolo Sileri ${ }^{2}$, Piero Rossi ${ }^{2}$, Laura Masuelli ${ }^{3}$, Massimo Fantini ${ }^{1}$, Monica Nanni ${ }^{1}$, \\ Luana Franceschilli², Giuseppe Sconocchia ${ }^{4}$, Giulia Lanzilli ${ }^{4}$, Roberto Arriga ${ }^{5}$, Giovanni Faggioni ${ }^{6}$, Florigio Lista ${ }^{6}$, \\ Augusto Orlandi ${ }^{7}$, Vittorio Manzari ${ }^{1}$, Achille Lucio Gaspari ${ }^{2}$, Andrea Modesti ${ }^{1}$ and Roberto Bei ${ }^{1{ }^{*}}$
}

\begin{abstract}
Background: Tumor associated antigens are useful in colorectal cancer (CRC) management. The ribosomal $P$ proteins (P0, P1, P2) play an important role in protein synthesis and tumor formation. The immunogenicity of the ribosomal PO protein in head and neck, in breast and prostate cancer patients and the overexpression of the carboxyl-terminal P0 epitope (C-22 P0) in some tumors were reported.

Methods: Sera from 72 colorectal tumor patients (67 malignant and 5 benign tumors) were compared with 73 healthy donor sera for the presence of antibodies to CEA, EGFR, ErbB2 and ribosomal P proteins by western blotting or ELISA. Expression of the C-22 P0 epitope on tissues and colon cancer cells was determined by immunoperoxidase staining and indirect immunofluorescence/western blotting, respectively, employing MAb 2B2. Biological effects of MAb $2 B 2$ on colon cancer cells were assessed by the Sulforhodamine B cell proliferation assay, trypan blue exclusion test and cleaved caspase-3 detection. Fisher's exact test was used to compare the number of auto-antibodies positive patients with healthy donors. Variation in the C-22 P0 expression, and in the number of apoptotic cells was evaluated by Student's $t$-test. Variation in cell survival and cell death was evaluated by Newman-Keuls test.

Results: No significant humoral response was observed to CEA, EGFR and ErbB2 in CRC patients. Conversely, 7 out of 67 CRC patient sera reacted to ribosomal $P$ proteins. The prevalence of $P$ proteins auto-antibodies in CRC patients was significant. Five patients showed restricted P0 immunoreactivity, while two patients reacted simultaneously to all P proteins. The C-22 P0 epitope was homogenously expressed both in malignant tumors and the adjacent mucosa, but the intensity of expression was higher in the tumor. Starved colon cancer cells showed a higher C-22 P0 epitope plasma membrane expression compared to control cells. MAb 2B2 inhibited colon cancer cell growth and induced cell death in a dose dependent manner.
\end{abstract}

Conclusions: Our study shows a spontaneous humoral immune response to ribosomal PO protein in CRC patients and the inhibition of in vitro cancer cell growth after C-22 P0 epitope targeting. The ribosomal P0 protein might be a useful immunological target in CRC patients.

Keywords: Ribosomal P proteins, Colon cancer, Immune response, Antibodies

\footnotetext{
* Correspondence: bei@med.uniroma2.it

${ }^{1}$ Department of Clinical Sciences and Translational Medicine, University of Rome "Tor Vergata", Rome, Italy

Full list of author information is available at the end of the article
} 


\section{Background}

Colorectal cancer (CRC) is the most common form of cancer among those that affect the gastrointestinal tract and represents the third most frequent cancer in men and the second in women [1,2]. Despite advances in diagnosis and therapy, the survival rate of CRC depends on the stage being $90 \%$ for stage I and II, and $<11 \%$ for stage IV $[1,3]$. The process of CRC carcinogenesis is a multistep process characterized by mutations of several genes, which lead to an invasive and drug resistantphenotype of the tumor [4-8]. The identification of molecular and immunological targets is essential for improving diagnostic and therapeutic strategies for CRC management.

Tumor antigens expressed by cancer cells are able to elicit spontaneous immune response in cancer patients [9]. Many auto-antibodies have been proposed as diagnostic or prognostic markers in cancer patients although they recognize self-antigens that are overexpressed in tumors [10-14]. It is worth of note that the repertoire of auto-antibodies found in cancer patients partly covers that detected in patients with autoimmune diseases [9]. In addition, auto-antibodies represent useful serological markers in the diagnosis of the autoimmune disease [9]. The immune identification of self-antigens in cancer patients might have significant repercussions that go beyond the discovery of novel biomarkers, since auto-antibodies found in cancer patients can target crucial molecules involved in the carcinogenesis process [15].

Several tumor associated antigens have been shown to be useful in CRC patients. Among them, the most common is the carcinoembryonic antigen (CEA), a glycosylated membrane-bound protein of $180 \mathrm{kDa}$ expressed in a high percentage of several carcinomas, including colorectal, gastric, pancreatic, non-small cell lung and breast carcinomas. The high level tumor expression of CEA and its release in the blood make CEA suitable for using it as tumor marker, especially in patients with CRC $[16,17]$. Other CRC tumor markers include circulating RNA, MicroRNA, mutated DNA (APC, K-RAS, p53), aberrant methylated markers, CA 19-9, TPA, CA 72-4 and cytokeratin fragments [18-20]. The expression of the epidermal growth factor receptor (EGFR) and human epidermal growth factor receptor 2 (HER2 or ErbB2) are associated with poor prognosis in sporadic CRC, thus representing two important prognostic markers in addition to be employed for targeted-therapy [21,22].

The ribosomal P proteins (P0, $38 \mathrm{kDa}$; $1,19 \mathrm{kDa}$; P2, $17 \mathrm{kDa}$ ) are involved in the formation of the ribosomal stalk of the $60 \mathrm{~S}$ ribosomal subunit in eukaryotic cell, in which they regulate protein synthesis [23-27]. Recently, we demonstrated the spontaneous immunogenicity of the ribosomal P0 protein in head and neck, in breast and prostate cancer patients and the overexpression of the carboxyl-terminal epitope of P0 (C-22 P0) in head and neck and breast carcinomas [28-30]. The immunodominant C-22 P0 epitope was found to be located within the 22 amino acid C-terminal peptide shared by all three P proteins [31,32]. P0 exists as a free protein in the cytoplasm and on the surface of cancer cells $[28,33]$ and appears to promote tumor formation [34]. Autoantibodies against $\mathrm{P}$ proteins have been identified for the first time in systemic lupus erythematosus (SLE) [35]. It was also found that the mRNA level of the P0 was greater in primary colon carcinoma than in paired adjacent normal colon epithelium [36].

In the present study, we investigated the humoral immune response to ribosomal $P$ proteins, CEA, EGFR and ErbB2 in CRC patients and the expression of the C-22 $\mathrm{P} 0$ epitope in colon cancer tissues. We also assessed the C-22 P0 epitope expression in two colon adenocarcinoma cell lines and the in vitro effect of a monoclonal antibody (MAb 2B2) which recognizes this epitope on the growth of colon cancer cells.

\section{Methods}

\section{Cell lines, antibodies and proteins}

Colon adenocarcinoma cells (HT29 and SW260) were maintained in RPMI 1640 containing 10\% fetal bovine serum, $100 \mathrm{U} / \mathrm{ml}$ penicillin and $100 \mu \mathrm{g} / \mathrm{ml}$ streptomycin (complete medium). Cells were grown at $37^{\circ} \mathrm{C}$ in a humidified incubator with an atmosphere of $5 \% \mathrm{CO}_{2}$. NIH3T3 cells encoding normal rat Neu (LTR-Neu) have been previously characterized and kindly provided by Dr. Eddi Di Marco (Istituto Tumori di Genova) [37]. NIH3T3 cells transfected with expression vectors for human coding sequences of human ErbB family receptors, including LTR-EGFR and LTR-ErbB2, as well as antiEGFR and anti-ErbB2 antibodies were previously described and kindly provided by Dr. Matthias Kraus [38]. MAb 2B2 is an IgG2a monoclonal antibody, which recognizes the C-22 P0 epitope [28]. Prokaryotic recombinant proteins (P0, P1, P2 and GST), and method of determining the MAb isotype were previously described $[28,29,39]$. Protein concentration was determined by Bradford protein assay (Bio-Rad, Hercules, CA, USA) [40]. Carcinoembryonic antigen (CEA) was purchased from Vitro Diagnostic Inc (Littleton, CO). The anti-CEA MAb R4 was previously described [41]. Sulforhodamine B, goat anti-human and anti-mouse IgG peroxidase-conjugated antibodies were purchased from Sigma (Milan, Italy). Goat anti-mouse IgG Alexa fluor-488-conjugated antibody was purchased from Life Technologies ${ }^{\mathrm{Tm}}$ Molecular Probes (Oregon, USA). Anti-human CD3 and anti-human CD20 antibodies were purchased from Ventana Medical System Inc (Tucson, AZ, USA). The anti-activated caspase-3 polyclonal antibody was purchased from Cell Signalling Technology (MA, USA). The purified mouse IgG2a (kappa) 
UPC10 was purchased from Cappel/Organon Teknika Corporation (West Chester, PA, USA) and used as control.

\section{Tissues and sera}

Tissues and sera of patients were obtained according to the ethical guidelines of the Policlinico of Tor Vergata "PTV", Rome. Sera from 72 patients with colorectal tumors (colon carcinoma, $\mathrm{n}=39$; rectal carcinoma, $\mathrm{n}=16$; sigmoid carcinoma, $\mathrm{n}=5$; recto-sigmoid carcinoma, $\mathrm{n}=$ 7; colon adenoma, $\mathrm{n}=5$ ) were collected and compared with 73 healthy donor sera, collected from blood donors from the University of Rome "Sapienza" transfusion center [24 women (mean age: $45.2 \pm 14.4$ ) and 49 men (mean age: $47.2 \pm 10.7)$ ]. Sera were obtained after informed consent and kept at $-20^{\circ} \mathrm{C}$ until evaluation. The clinical stage of cancer patients included stage I $(n=15)$, stage IIa $(n=22)$, stage IIb $(n=2)$, stage IIIa $(n=1)$, stage IIIb $(n=21)$, stage IIIc $(n=4)$ and stage IV $(n=2)$. Tissue specimens from 23 cancer patients were also obtained. Adjacent normal mucosa was informative in 17 specimens.

\section{Detection of anti-Rib-P antibodies}

DRG ${ }^{\circ}$ Anti-Rib-P ELISA kit (EIA-3582, DRG Instruments $\mathrm{GmbH}$, Germany) was employed for detection of IgG auto-antibodies against ribosomal $\mathrm{P}$ proteins ( $\mathrm{P}$, $\mathrm{P} 1, \mathrm{P} 2)$. The analysis was performed according to the manufacturers' instructions. Values of anti-rib-P antibodies above $10 \mathrm{U} / \mathrm{ml}$ were above the cut-off and thus were considered positive.

\section{Western blotting}

Electrophoresis of purified recombinant P-GST (P0, P1, P2), GST and CEA proteins (0.5 $\mu$ glane) as well as NIH3T3 and NIH-LTR-EGFR and LTR-ErbB2 cell extracts $(100 \mu \mathrm{g} / \mathrm{lane})$ was carried out in denaturing 10$12 \%$ SDS polyacrylamide gels. Following electrophoresis, proteins were transferred to nitrocellulose membranes at $40 \mathrm{~V}$ for $1 \mathrm{~h}$. After blocking in a washing solution (1\% Tween-20 in PBS, $\mathrm{pH} 7.6$ ) containing 5\% nonfat dry milk, membranes were incubated overnight at $4^{\circ} \mathrm{C}$ with either human sera or specific monoclonal and polyclonal antibodies. Human sera were initially titrated at 1:25, 1:50 and 1:100 dilutions [30,42]. The 1:100 dilution was chosen for further experiments since it was the highest serum concentration lacking background reactivity. After extensive washings, membranes were incubated with goat anti-human IgG or goat anti-mouse or anti-rabbit IgG peroxidase-conjugated antibodies. The immune complexes were visualized by the Supersignal West Pico chemiluminescence kit (Pierce, Rockford, IL, USA) [43]. Criteria of serum positivity toward a given antigen consisted in the appearance of an immunoreactive band co-migrating with that detected by the positive control antibody. The intensity of coloring of the specific immunoreactive bands was expressed as densitometric unit (s) (DU) and was obtained using the NIH Pro-Image 1.5 software after blot scanning.

\section{Immunohistochemical analysis}

Expression of the C-22 P0 epitope on tissues was determined by immunoperoxidase staining after incubation with MAb $2 \mathrm{~B} 2$ or UPC10 $(1 \mu \mathrm{g} / \mathrm{mL})$ as previously described [28,29]. No reactivity was observed using UPC10 (data not shown). Semiquantitative C-22 P0 epitope expression in human tissues was estimated at x200 magnification in at least 10 fields by two investigators in a blind fashion, who used a previously described score system with minor modifications $[44,45]$. C-22 P0 expression levels (negative, 0; weakly positive, 1 ; moderately positive, 2 ; strongly positive, 3 ) were scored. The interobserver reproducibility was $>95 \%$. Paraffin sections were also processed for anti-CD3 and antiCD20 antibodies analyses using a Ventana XT automated slide stainer (Ventana Medical Sistem Inc, Roche, Tucson AZ, USA) according to manufacturer instruction [46,47]. The ratio between anti-CD3+ and anti-CD20+ cells was evaluated.

\section{Immunofluorescence staining of the C-22 P0 epitope on colon cancer cell lines (SW260, HT29)}

Indirect immunofluorescence was carried out on native cells. Briefly, cells $\left(5 \times 10^{4}\right)$ were grown for 48 hours with or without $10 \%$ serum. Cells were detached by incubation with $0.02 \%$ EDTA in PBS and incubated with MAb 2B2 or UPC10 $(1 \mu \mathrm{g} / \mathrm{ml})$ for 1 hour at room temperature [48]. After washes with cold PBS, cells were labeled with goat anti-mouse IgG Alexa fluor-488-conjugated antibody (Life Technologies $^{\text {Tw }}$ Molecular Probes, Oregon, USA) for $45 \mathrm{mi}-$ nutes at room temperature, washed and immediately observed with an Olympus BX51 microscope.

\section{Sulforhodamine B (SRB) assay}

For cell proliferation assay, SW260 and HT29 cells $\left(1 \times 10^{4}\right.$ cells/well) were incubated in serum-free RPMI containing $0.2 \%$ BSA containing MAb 2B2 $(20,5,1 \mu \mathrm{g} / \mathrm{ml})$ or UPC10 $(20 \mu \mathrm{g} / \mathrm{ml})$. MAbs were replenished every $24 \mathrm{~h}$. All treatments were performed in triplicate. Survival of cells was assessed by the Sulforhodamine B cell proliferation assay after 72 hours, as previously described [49]. The percentage survival of the cultures treated with MAb 2B2 was calculated by normalization of their O.D. values to those of control cultures treated with UPC10 [50].

\section{Trypan blue exclusion test}

For trypan blue exclusion test, SW260 and HT29 cells (5 x $10^{4}$ cells/well) were seeded in 24-well plates. After 24 hours, cells were incubated in serum-free RPMI containing 0.2\% 
BSA and MAb 2B2 $(20,5,1 \mu \mathrm{g} / \mathrm{ml})$ or UPC10 $(20 \mu \mathrm{g} / \mathrm{ml})$. Antibodies were replenished every 24 hours. All treatments were performed in triplicate. After 72 hours, adherent as well as suspended cells of each well were harvested and stained with trypan blue (Sigma, Milan, Italy) and counted with an optic microscope. The experiments were repeated three times. Percentage of cell death was determined compared to the total number of cells.

\section{In situ detection of apoptosis}

For in situ detection of programmed cell death, SW260 and HT29 cells were seeded at $5 \times 10^{4}$ cells/well in 8well chamber-slides. After 24 hours cells were incubated in serum-free RPMI containing $0.2 \% \mathrm{BSA}$ and MAb 2B2 $(20 \mu \mathrm{g} / \mathrm{ml})$ or UPC10 $(20 \mu \mathrm{g} / \mathrm{ml})$. Antibodies were replenished every 24 hours. After 48 hours, cells were fixed in $4 \%$ paraformaldehyde for $15 \mathrm{~min}$, washed and incubated with the anti-activated caspase- 3 polyclonal antibody for 1 hour. After additional washings the cells were labeled with a goat anti-rabbit IgG Alexa fluor594-conjugated antibody for $30 \mathrm{~min}$ [51]. After a third washing, cells were then incubated with $0.1 \mu \mathrm{g} / \mathrm{ml}$ Hoechst 33342 and mounted under a coverslip with glycerol. Cells treated for 16 hours with staurosporine $1 \mu \mathrm{M}$ were used as positive control. The percentage of apoptotic cells was calculated by determining the ratio between the cells positive for activated caspase- 3 and the total number of cells present in five randomly chosen microscopic fields. Cell counts were done in a blinded fashion.

\section{Statistical analysis}

Fisher's exact test was used to compare the number of patients with positive levels of antibodies compared to healthy donors. Variation in the C-22 P0 expression and in the number of apoptotic cells was evaluated by Student's $t$-test. Statistical associations were considered significant at a p-value $\leq 0.05$.

Data distribution of cell survival and cell death was preliminarily verified by the Kolmogorov-Smirnov test and data sets were analyzed by one-way analysis of variance (ANOVA) followed by Newman-Keuls test. Values with $\mathrm{p} \leq 0.05$ were considered significant.

\section{Results}

Immunoreactivity of colorectal cancer (CRC) patient sera to ribosomal $P$ proteins, CEA, EGFR and ErbB2

Sera from colorectal cancer $(n=67)$ and colon benign tumor patients $(n=5)$ were analyzed for the presence of auto-antibodies to ribosomal $\mathrm{P}$ proteins (P0/P1/P2), CEA, EGFR and ErbB2. The clinicopathological characteristics of patients are reported in Table 1. Patients serum reactivity was compared to that of healthy donors $(n=73)$. To detect antibodies to ribosomal P proteins,
Table 1 Clinicopathological characteristics of patients

\begin{tabular}{ll}
\hline Patients (number) & $\mathbf{7 2}$ \\
\hline Age (years) & 71 \\
Media & $43-87$ \\
Range & \\
Gender & 42 \\
Male (number) & 30 \\
Female (number) & \\
Tumor & 5 \\
Adenoma & 39 \\
Colon carcinoma & 16 \\
Rectal carcinoma & 5 \\
Sigmoid carcinoma & 7 \\
Recto-sigmoid carcinoma & \\
Stage of disease & 15 \\
I & 22 \\
IIA & 2 \\
IIB & 21 \\
IIIA & 2 \\
IIIB & 1 IIC \\
IV & 2 \\
\hline
\end{tabular}

the anti-Rib-P Ab ELISA kit was employed. The presence of serum antibodies to CEA and EGFR or ErbB2 was assessed by western blotting, employing CEA extracted from tumors, and NIH3T3 cells transfected with expression vectors encoding for sequences of human EGFR and ErbB2, respectively. Representative experiments are shown in Figure 1.

None of the sera from healthy donors displayed reactivity to P proteins (Table 2). Conversely, 7 out of 67 sera from CRC patients reacted to ribosomal $P$ proteins. The prevalence of anti-P proteins auto-antibodies in CRC patients was significant compared to that of healthy donors $(\mathrm{p}=0.0048)$ (Table 2$)$. The antibody response to anti-P proteins was not associated with the stage of disease. Indeed, patients with anti-P proteins antibodies showed either an early (T1N0, T2N0) or an advanced stage [T3N0 $(\mathrm{n}=2)$ and 3 patients with T3N1 $(\mathrm{n}=3)$ ] of disease. In addition, no antibody response to ribosomal $\mathrm{P}$ proteins was observed in patients with adenoma.

Conversely, no humoral immune response to CEA was observed in both colorectal cancer patients and healthy donors (data not shown). The anti-CEA MAb R4 was employed as a positive control for CEA detection (Table 2).

Two of 67 cancer patients showed antibodies against EGFR (Table 2). It is important to note that one of these two patients also had antibodies against ribosomal $\mathrm{P}$ 


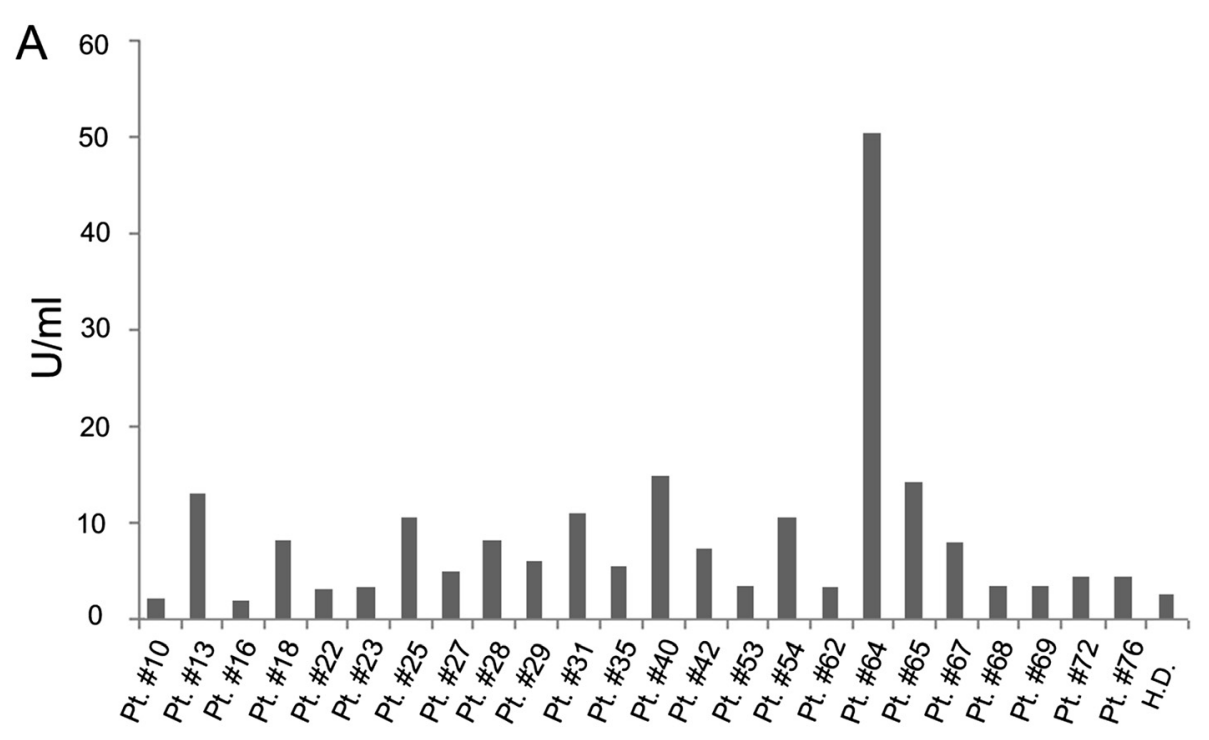

B

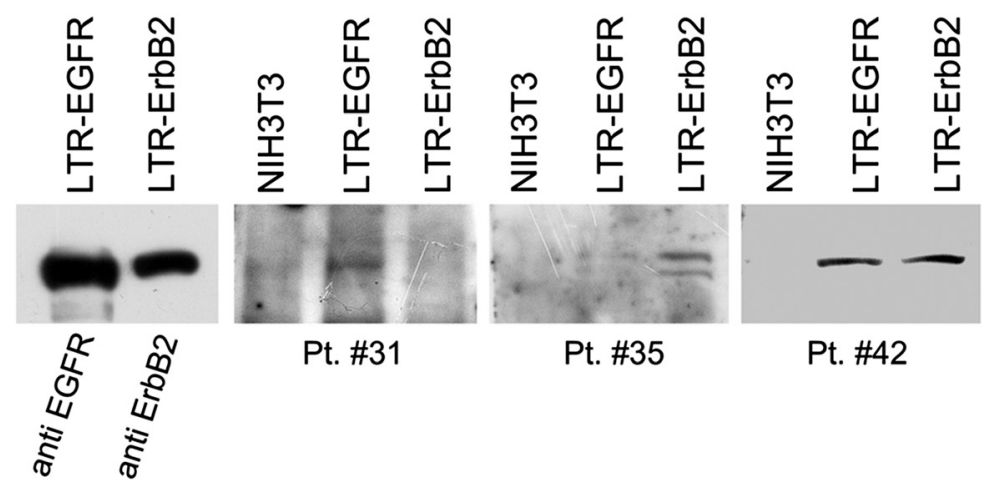

Figure 1 Humoral immune response to ribosomal P proteins, EGFR and ErbB2 in colorectal cancer patients. Analysis of the humoral immune response to ribosomal P proteins employing the Rib-P Ab ELISA kit (Panel A) and to EGFR and ErbB2 by western blotting employing NIH3T3 cells coding for EGFR (LTR-EGFR) and ErbB2 (LTR-ErbB2) (Panel B). Pt. = patient; H.D. = healthy donor.

proteins (data not shown). This patient was diagnosed with cancer of the rectum at an early stage of disease (T1N0). None of the sera from healthy donors displayed reactivity to EGFR or ErbB2. Conversely, one of 5 patients with a benign tumor and one of 67 cancer patients had antibodies to ErbB2 (Table 2). One patient with an advanced stage of disease (T3N2b) displayed a simultaneous reactivity to EGFR and ErbB2.

Our results indicate that the ribosomal $\mathrm{P}$ proteins are more immunogenic than CEA and ErbB receptors in CRC patients. The humoral response to $P$ proteins and the C-22 P0 epitope tumor expression were then further investigated. In addition, the in vitro effect of MAb 2B2 which recognizes the C-22 P0 epitope on growth of colon cancer cells was analyzed.

\section{Individual or simultaneous serum reactivity to ribosomal proteins in colorectal cancer patients}

The Anti-Rib-P Ab ELISA kit, containing a mixture of the three native $\mathrm{P} 0, \mathrm{P} 1$ and $\mathrm{P} 2$ ribosomal proteins, does not allow to identify which $\mathrm{P}$ protein is recognized by serum antibodies. To define the individual $\mathrm{P}$ protein

Table 2 Humoral immune response to ribosomal $P$ proteins, CEA, EGFR and ErbB2 in colorectal cancer patients

\begin{tabular}{|c|c|c|c|c|c|c|c|c|}
\hline Subjects & Rib-P proteins (P0/P1/P2) & $\mathrm{p}$ & CEA & $\mathrm{p}$ & EGFR & $p$ & ErbB2 & $p$ \\
\hline Healthy Donors & $0 / 73$ & $n \cdot s^{a}$ & $0 / 73$ & n.s & $0 / 73$ & n.s & $0 / 73$ & n.s \\
\hline Patients: Benign tumor & $0 / 5$ & n.s & $0 / 5$ & n.s & $0 / 5$ & n.s & $1 / 5$ & n.s \\
\hline Patients: Malignant tumor & $7 / 67$ & $0.0048^{b}$ & $0 / 67$ & n.s & $2 / 67$ & n.s & $1 / 67$ & n.s \\
\hline
\end{tabular}


immunoreactivity of the seven anti-P proteins positive sera, each serum was analyzed for its reactivity to individual recombinant ribosomal $\mathrm{P}$ proteins $(\mathrm{P} 0, \mathrm{P} 1$ and P2) by western blotting. Criterion of positivity was the appearance of an immune-reactive band in the serum sample, co-migrating with the one visualized by the MAb 2B2, which recognizes the P0, P1 and P2 proteins. The reactivity of sera to recombinant ribosomal $\mathrm{P}$ proteins is shown in Figure 2. The presence of specific antibodies against ribosomal $\mathrm{P}$ proteins is shown in Table 3. All seven patients had auto-antibodies to P0 protein. Five patients showed immunoreactivity only to P0, while two patients had simultaneous auto-antibodies to P0, P1 and P2 proteins. No correlation between the concentration of auto-antibodies, detected employing the anti-Rib$P$ ELISA kit and the density values of immunoreactive bands with sera by western blotting was observed (data not shown).

\section{Expression of the C-22 P0 epitope in human normal and pathological colorectal tissues}

To assess the state of the C-22 P0 epitope expression in tumors, immunohistochemical analysis of colorectal cancer tissues was performed by immunostaining with MAb 2B2 and compared to that of adjacent non-neoplastic mucosa. We evaluated both the intensity and homogeneity of the C-22 P0 epitope expression in 23 malignant tumors and 17 adjacent mucosa samples. Representative immunostaining of the C-22 P0 epitope is showed in Figure 3 (Panel A). The C-22 P0 epitope was expressed homogenously both in the tumor and adjacent normal mucosa, but the intensity of expression was significantly higher in the tumor than in the adjacent mucosa $(\mathrm{p}<$ 0.001) (Figure 3, Panel B). It is worth noting that the C-22 P0 epitope was found to be also expressed by fibroblasts, endothelial cells and leukocytes present in the tumor and the normal mucosa.

Tumor specimens from 5 of the 7 patients positive for anti-P0 antibodies were analyzed for the expression of tumor infiltrating $\mathrm{T}$ and B lymphocytes. Subserosal deep infiltration of tumor cells was characterized by the presence of abundant inflammatory cells, with a large prevalence of $\mathrm{CD} 3+\mathrm{T}$ lymphocytes and a small percentage of CD20+ B lymphocytes (mean ratio 5:1) (Figure 3, Panel C).

Expression and subcellular localization of the C-22 P0 epitope in colon adenocarcinoma cell lines (SW260 and HT29)

The expression of the C-22 P0 epitope on colon adenocarcinoma cells (SW260 and HT29) was analyzed by western blotting. MAb 2B2 detected a molecular weight product of $38 \mathrm{kDa}$ consistent with the molecular weight of the ribosomal P0 protein on both cell lines (Figure 4, Panel A).

We previously demonstrated that the C-22 P0 epitope is localized on the plasma membrane of not fixed and not permeabilized tongue and pharynx cancer cells under conditions of stress, such as the absence of serum in the culture medium [28]. To determine whether the serum deprivation induced a similar effect on colon cancer cells, SW260 and HT29 cells were grown in the presence and absence of serum and indirect immunofluorescence was carried out employing MAb 2B2. As shown in Figure 4, Panel B, SW260 and HT29 cells grown without serum, have a higher expression of the C-22 P0 epitope on the plasma membrane compared to cells cultured in the presence of serum.

\section{Biological effects of MAb 2B2 on colon adenocarcinoma cells}

As shown above, cells under conditions of stress showed increased expression of the C-22 P0 epitope on the plasma membrane. Therefore, we examined whether MAb 2B2 recognizing this epitope was able to inhibit the growth of colon adenocarcinoma cells. For this purpose, SW260 and HT29 colon cancer cells were seeded in serum-free culture medium containing $0.2 \%$ BSA and incubated with MAb 2B2 at different concentrations (20, 5 and $1 \mu \mathrm{g} / \mathrm{ml})$. The antibody UPC10 at $20 \mu \mathrm{g} / \mathrm{ml}$ was used as matched isotype control antibody.

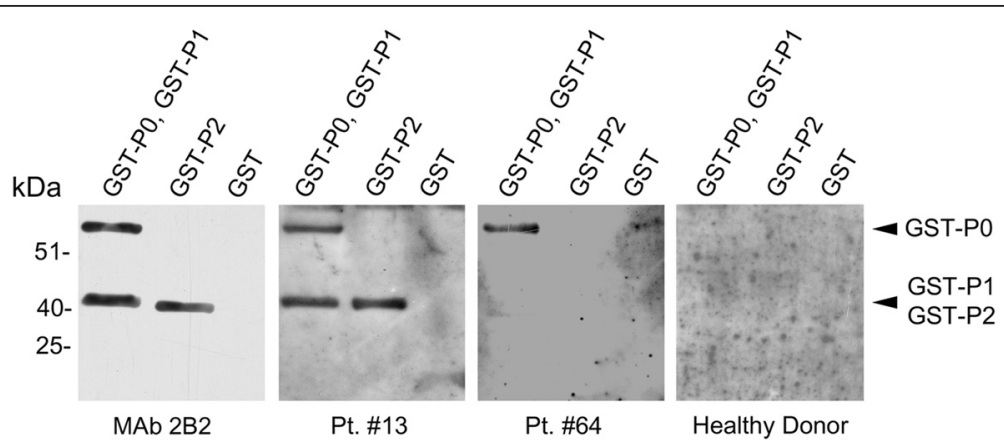

Figure 2 Humoral immune response to individual ribosomal P proteins. Analysis of individual ribosomal P proteins was performed by western blotting. The monoclonal antibody (MAb) 2B2 was used as positive control. The protein GST was used as a negative control for the recombinant fusion proteins GST-P0, GST-P1 and GST-P2. Pt. = patient. 
Table 3 Presence of auto-antibodies directed against ribosomal $\mathbf{P}$ proteins

\begin{tabular}{lll}
\hline Patient \# & $\begin{array}{l}\text { Rib-P assay } \\
(\mathbf{U} / \mathbf{m l})\end{array}$ & $\begin{array}{l}\text { Western blotting using } \\
\text { individual recombinant } \\
\text { P proteins }\end{array}$ \\
\hline 13 & 13.21 & P0, P1, P2 \\
25 & 10.62 & P0 \\
31 & 10.93 & P0 \\
40 & 14.74 & P0, P1, P2 \\
54 & 10.56 & P0 \\
64 & 50.25 & P0 \\
65 & 14.12 & P0 \\
\hline
\end{tabular}

MAb 2B2 significantly inhibited cell growth in both cell lines in a dose dependent manner compared to control antibody. When used at higher concentration (20 $\mu \mathrm{g} / \mathrm{ml}), \mathrm{MAb} 2 \mathrm{~B} 2$ decreased cell growth of $45 \%$ in SW260 cells and 30\% in HT29 cells. The mean of the results of three independent experiments is reported in Figure 5, Panel A.

A trypan blue exclusion test and in situ detection of apoptosis were carried out in order to evaluate the effect of MAb 2B2 on cell death of colon carcinoma cells. MAb 2B2 significantly increased the percentage of cell death in a dose dependent manner as compared to control antibody (UPC10 at $20 \mu \mathrm{g} / \mathrm{ml}$ ) (Figure 5, Panel B). The percentage of cell death upon MAb 2B2 treatment was $11.2 \%(5 \mu \mathrm{g} / \mathrm{ml})$ and $19.6 \%(20 \mu \mathrm{g} / \mathrm{ml})$ in SW260 cells and $14.1 \%(5 \mu \mathrm{g} / \mathrm{ml})$ and $21.9 \%(20 \mu \mathrm{g} / \mathrm{ml})$ in HT29 cells.

SW260 and HT29 cells were labeled with an antiactivated-caspase- 3 antibody after treatment with $\mathrm{MAb}$ 2B2 $(20 \mu \mathrm{g} / \mathrm{ml})$ or UPC10 $(20 \mu \mathrm{g} / \mathrm{ml})$ for 48 hours or, as positive control, with staurosporine $(1 \mu \mathrm{M})$ for 16 hours. Figure 5, Panel $\mathrm{C}$ shows representative pictures of immunolabeled SW260 and HT29 cells. According to activated caspase- 3 positivity, the treatment with UPC10 had no relevant effect on the induction of apoptosis in both SW260 (0.3\%) and HT29 (0.6\%) cells. In comparison, the percentage of apoptotic cells was $6.3 \%(\mathrm{p}<$ $0.001)$ and $6.2 \%(\mathrm{p}<0.001)$ in MAb 2B2-treated SW260 and HT29, respectively. Treatment with staurosporine resulted in apoptotic rates of $70.1 \%$ and $77 \%$ in SW260 and HT29, respectively.

\section{Discussion}

One of the most important challenges in the fight against cancer is to find novel biological markers that can help to improve diagnosis and therapy. Several tumor antigens are recognized by the immune system and thus might represent biological markers for the early detection of cancer [52]. The complexity in the diagnosis of CRC might be improved by the discovery of new diagnostic markers [53]. Several tumor markers have been identified in CRC [54]. Recently, it has been evaluated

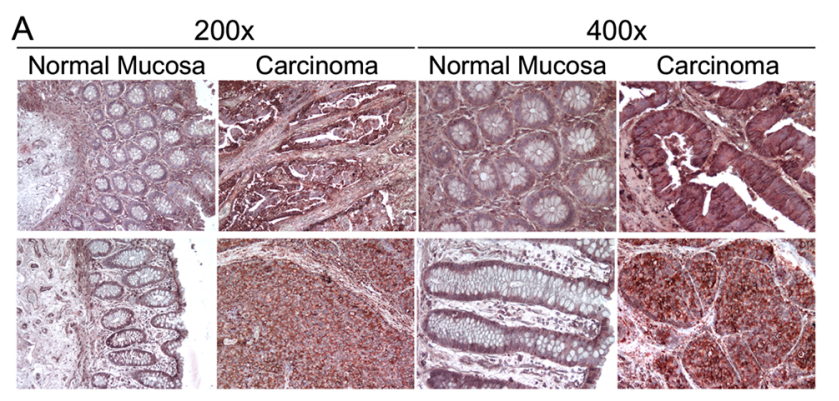

B
C

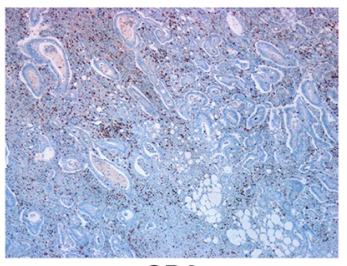

CD3

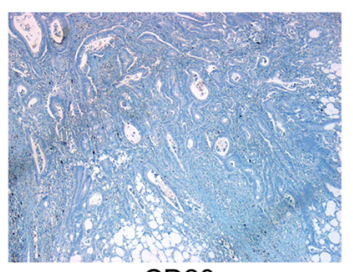

CD20

Figure 3 Expression of the C-22 P0 epitope in normal mucosa and colorectal cancer. Panel A. Immunohistochemical detection of the C-22 P0 epitope by MAb 2B2. Panel B. Intensity of the C-22 P0 epitope expression in colorectal tumors and in the adjacent normal mucosa. Bar graph shows a semiquantitative evaluation of the C-22 P0 epitope expression in colorectal tumors and the adjacent normal mucosa ( $p<0.001)$. Panel $\mathbf{C}$. Immunohistochemical detection of CD3+ T lymphocytes and CD20+ B lymphocytes in a colon adenocarcinoma from a patient positive for anti-P0 antibodies (40x). 


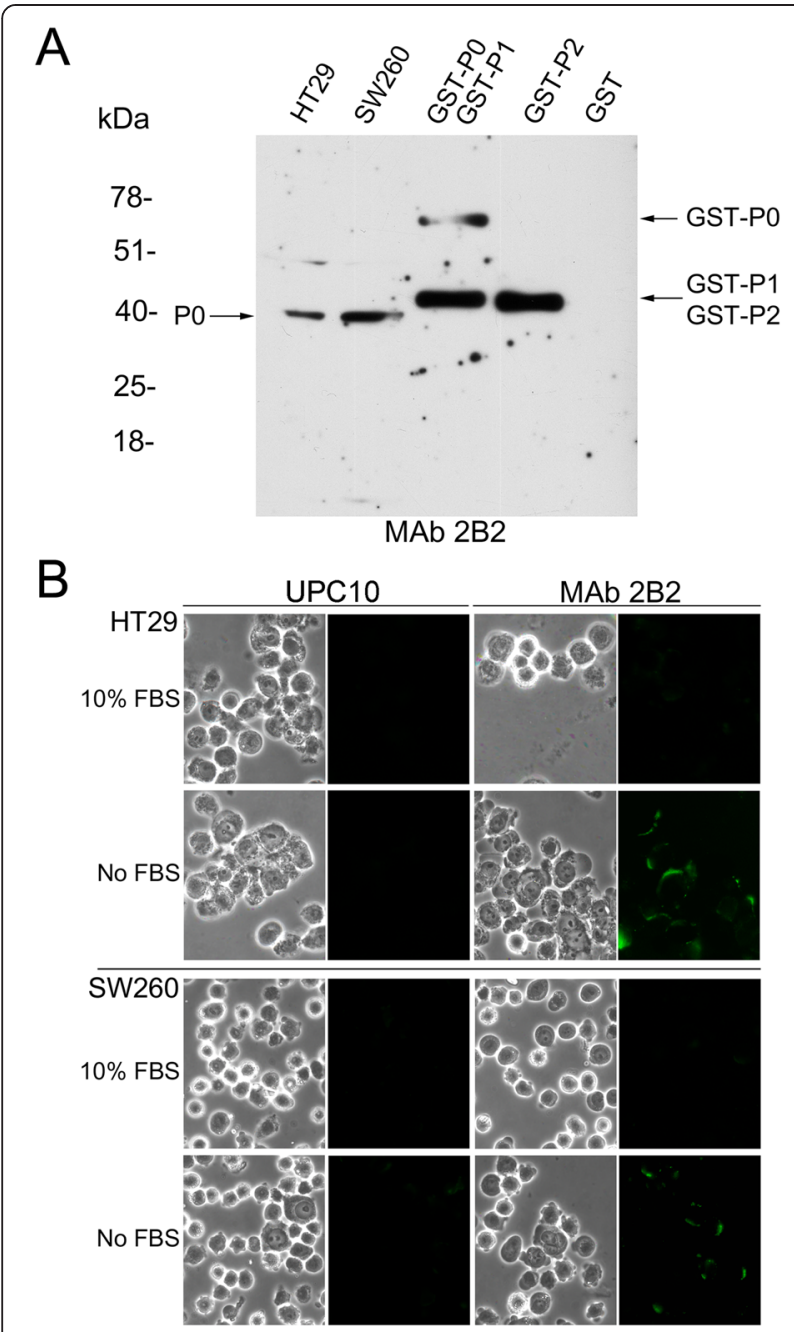

Figure 4 Expression and subcellular localization of the C-22 PO epitope in colon adenocarcinoma cell lines (SW260 and HT29). Panel $\mathbf{A}$ The expression of the C-22 P0 epitope was determined by western blotting. The recombinant proteins GST-P0/P1/P2 were used as positive control. Panel B. Indirect immunofluorescence was performed using not fixed and not permeabilized SW260 and HT29 cells. Cell morphology was determined by phase-contrast microscopy. The antibody UPC 10 was used as a negative control.

the presence of auto-antibodies to tumor associated antigens as a biological marker. It has been described that auto-antibodies are elicited during the transition from benign neoplasm or chronic inflammatory disease to malignancy [55]. Auto-antibodies to CENP-F and P62 appear to be linked to the transition from chronic liver disease to hepatocellular carcinoma [56]. In our study, we evaluated the humoral immune response to ribosomal P0, P1 and P2 proteins, CEA, EGFR and ErbB2 in CRC patients and compared to that in healthy donors.

Among the antigens analyzed, the ribosomal P0 protein was found to be the most immunogenic antigen in CRC patients. Indeed, patients with CRC showed a significant humoral response to ribosomal P0 protein compared to healthy donors. On the other hand, a significant immune response to CEA, EGFR and ErbB2 was not observed. The spontaneous immunogenicity of the ribosomal P0 protein had already been observed in previous studies performed in our laboratory [28-30]. The analysis of the immune response with head and neck cancer patients showed a significant response against the ribosomal P0 protein. Immunity to P0 protein (7/40) was associated with malignancy and advanced disease stage, but it was not dependent on the C-22 P0 epitope overexpression [28]. In prostate cancer patients, a significant humoral response to P0 protein correlated with the blood release of the prostate specific antigen (PSA) after radiotherapy [30]. However, in CRC patients we could not observe any association between the immune response and the stage of the disease.

Auto-antibodies against $\mathrm{P}$ proteins have been identified for the first time in systemic lupus erythematosus (SLE) where they can induce damage of the central nervous system, hepatitis and nephritis. In particular, anti-P proteins antibodies appear to be associated with other forms of SLE with psychosis, where the antibody titer increases before and during the active phase of psychosis [35]. However, patients with CRC displaying P0 protein autoantibodies, did not show liver or kidney alterations, neither were affected by psychosis. The lack of normal tissue damage by spontaneously elicited anti-P0 antibodies in CRC patients might be due to a low serum autoantibodies concentration. Patients with SLE might have a higher titer of anti-P0 antibodies compared to cancer patients. In addition, some reports failed to find any relationship of anti-P antibodies and neuropsychiatric SLE or liver and renal diseases in SLE patients [57,58].

In our study, we also demonstrated, by immunohistochemistry employing MAb 2B2, that the CRC tissue shows an overexpression of the C-22 P0 epitope compared to adjacent normal mucosa. The C-22 P0 epitope was found to be overexpressed in head and neck [28], and breast [29] cancers. In addition earlier studies reported high level of P0 messenger RNA in hepatocellular and colon carcinomas [36]. In gynecological tumors, the ribosomal P0 protein expression did not correlate with the stage of disease although the expression increased primarily in the cancerous tissue and not in precancerous lesion [59]. The ribosomal protein P0 appears to promote tumor formation [34]. Indeed, it was observed that it is able of binding the protein GCIP (interacting protein cyclin D1 and GRAP2), which is a tumor suppressor localized in the nucleus, which inhibits the phosphorylation of RB (retinoblastoma protein). In addition, P0 also promotes the increased expression of cyclin D1 and cell proliferation, when it is overexpressed [34].

Different monoclonal antibodies have been approved for the treatment of hematopoietic and solid tumors 


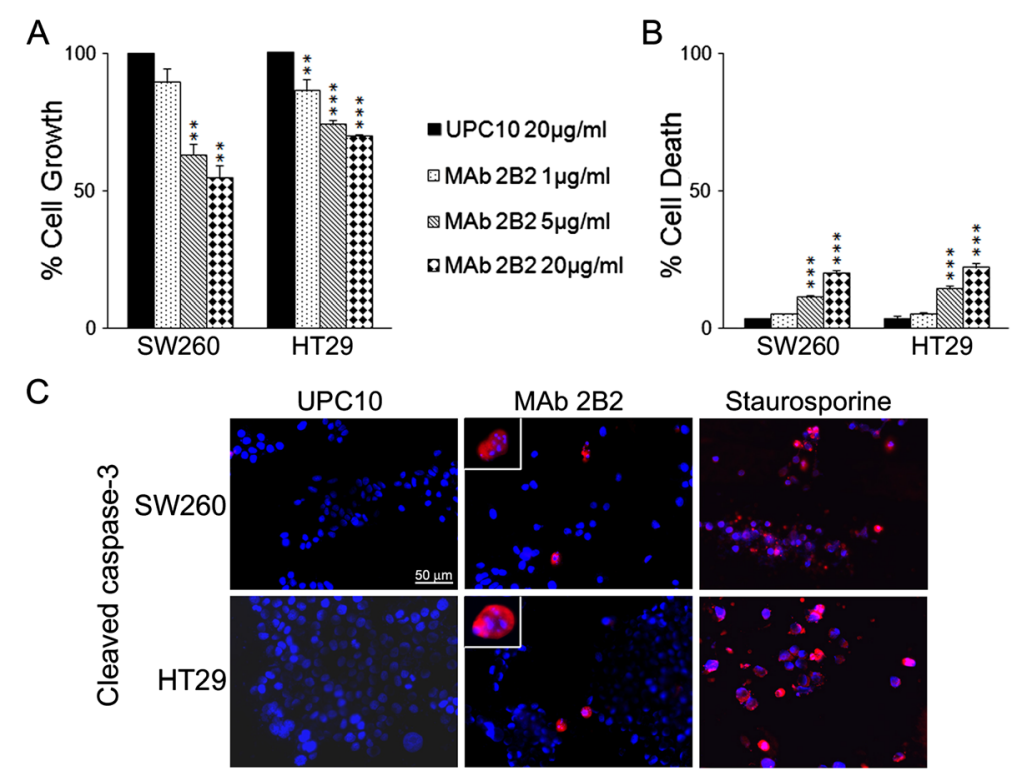

Figure 5 Effect of MAb 2B2 recognizing the C-22 P0 epitope on colon adenocarcinoma cells. Panel A. Cells growth was assessed by sulforhodamine B assay. SW260 and HT29 cells were treated with MAb 2 B2 at different concentrations $(20,5,1 \mu \mathrm{g} / \mathrm{ml})$. The antibody UPC10 was used as control $(20 \mu \mathrm{g} / \mathrm{ml})$. The results are the mean of three independent experiments $\left({ }^{* *} p<0.01,{ }^{* * *} p<0.001\right)$. Panel $\mathbf{B}$. Trypan blue exclusion test was

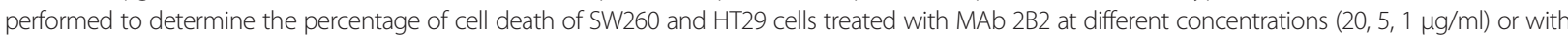
the antibody UPC10 $(20 \mathrm{\mu g} / \mathrm{ml})$. The results are the mean of three independent experiments $\left({ }^{* * *} \mathrm{p}<0.001\right)$. Panel $\mathbf{C}$. In situ detection of apoptosis. Induction of apoptosis in SW260 and HT29 cells, as assessed by immunolabeling with an anti-activated caspase-3 antibody, after treatment with MAb 2B2 $(20 \mu \mathrm{g} / \mathrm{ml})$ or UPC10 $(20 \mu \mathrm{g} / \mathrm{ml})$ for 48 hours or, as positive control, with staurosporine $(1 \mu \mathrm{M})$ for 16 hours. Nuclei were counterstained with Hoechst.

[60]. MAbs can bind antigens differentially expressed by cancer cells compared to the normal counterparts and block directly or through immune system the growth of cancer cells [60]. Accordingly, we evaluated the C-22 P0 epitope expression on the plasma membrane of colon cancer cells, since we earlier demonstrated that this epitope is expressed on the membrane of tongue and pharynx cancer cells under conditions of stress [28]. We observed that colon cancer cells grown without serum, showed a higher expression of the C-22 P0 epitope on the plasma membrane compared to cells cultured in the presence of serum. It should be considered that solid tumors could grow in an adverse microenvironment characterized by improper vascularization and poor oxygen and nutrient supply [61]. In addition, it was demonstrated that the ribosomal P0 protein is expressed in the membrane in Jurkat cells and T-lymphoblasts, and becomes the target for anti-P0 auto-antibodies, which were internalized and caused cell apoptosis [62]. Anti-P0 antibodies were shown to penetrate into living hepatoma cells and cause cellular dysfunction in culture as well $[63,64]$. We previously demonstrated that BALB-neuT mice vaccinated with the human P0 protein had a significant delay of neu-mediated mammary carcinoma growth and that the extent of tumor growth interference in vivo was associated with high serum levels of antibodies, which recognize the murine P0 protein expressed on mouse mammary cancer cells [29].

Accordingly, we evaluated the biological effect of MAb $2 \mathrm{~B} 2$ on the in vitro growth of cancer cells. Here, we demonstrated that MAb 2B2 significantly inhibited human colon adenocarcinoma cell growth in a dose dependent manner. The inhibition of survival observed in MAb 2B2-treated cells could be due to both reduced proliferation and increased cell death. Therefore, we analyzed the effect of MAb 2B2 on colon cancer cells viability and apoptosis. We demonstrated that MAb 2B2 significantly reduced colon cancer cell viability and induced apoptosis in a dose dependent manner in both colon cancer cell lines.

Overall, our results indicate the potential usefulness of the ribosomal P0 protein as an immunological target in CRC patients, who spontaneously develop auto-antibodies to the P0 protein. Further studies should be performed to study the potential involvement of anti P0 auto-antibodies in cancer cells death. Our study showing for the first time a spontaneous humoral immune response to ribosomal P0 protein in CRC patients and the inhibition of in vitro cancer cell growth after C-22 P0 epitope targeting, might offer a potential tool for designing cancer vaccines 
targeting the P0 protein, in order to enhance the immune response for hampering tumor growth.

\section{Conclusions}

Our study shows for the first time a spontaneous humoral immune response to ribosomal P0 protein in CRC patients and the inhibition of in vitro cancer cell growth after C-22 P0 epitope targeting. The ribosomal P0 protein might be a useful immunological target in CRC patients.

\author{
Abbreviations \\ CEA: Carcinoembryonic antigen; EGFR: Epidermal growth factor receptor; \\ GST: Glutathione S-transferase.
}

\section{Competing interests}

The authors declare that they have no competing interests.

\section{Authors' contributions}

MB performed western blotting, cell proliferation and participated in the analysis of results. PS, PR, LF and ALG were the surgeons involved in collection of tissue samples and blood and critically revised the manuscript. LM performed indirect immunofluorescence and immunohistochemical analysis and analyzed the results. MF performed western and statistical analysis. MN performed western blotting and ELISA. GS, VM, AM, GF critically revised the manuscript. GL and RA prepared tissue specimens. AO supervised the immunohistochemical analysis and critically revised the manuscript. RB supervised the project and wrote the manuscript. All authors read and approved the final manuscript.

\section{Acknowledgements}

This study was partially supported by a grant from PRIN (R.B). Giuseppe Sconocchia was supported by an IG10555 grant awarded and the Italian Association for Cancer Research (AIRC).

\section{Author details}

'Department of Clinical Sciences and Translational Medicine, University of Rome "Tor Vergata", Rome, Italy. 'Department of Experimental Medicine and Surgery, University of Rome "Tor Vergata", Rome, Italy. 'Department of Experimental Medicine, University of Rome "Sapienza", Rome, Italy. ${ }^{4}$ Laboratory of Tumor Immunology and Immunotherapy, Institute of Translational Pharmacology, Department of Medicine, CNR, Rome, Italy. ${ }^{5}$ Department of Systems Medicine, University of Rome "Tor Vergata", Rome, Italy. ${ }^{6}$ Centro Studi e Ricerche Sanità e Veterinaria Esercito, Rome, Italy. ${ }^{7}$ Department of Biomedicine and Prevention, University of Rome "Tor Vergata", Rome, Italy.

Received: 14 November 2014 Accepted: 9 March 2015

\section{Published online: 28 March 2015}

\section{References}

1. Haggar FA, Boushey RP. Colorectal cancer epidemiology: incidence, mortality, survival, and risk factors. Clin Colon Rectal Surg. 2009;22:191-7.

2. Tárraga López PJ, Albero JS, Rodríguez-Montes J. Primary and secondary prevention of colorectal cancer. Clin Med Insights Gastroenterol. 2014;7:33-46.

3. Siegel R, DeSantis C, Virgo K, Stein K, Mariotto A, Smith T, et al. Cancer treatment and survivorship statistics, 2012. CA Cancer J Clin. 2012;62:220-41.

4. Gryfe R, Swallow C, Bapat B, Redston M, Gallinger S, Couture J. Molecular biology of colorectal cancer. Curr Probl Cancer. 1997;21:233-300.

5. Vogelstein B, Fearon ER, Hamilton SR, Kern SE, Preisinger AC, Leppert M, et al. Genetic alterations during colorectal-tumor development. N Engl J Med. 1988;319:525-32.

6. Powell SM, Zilz N, Beazer-Barclay Y, Bryan TM, Hamilton SR, Thibodeau SN, et al. APC mutations occur early during colorectal tumorigenesis. Nature. 1992:359:235-7.

7. Miyaki M, Konishi M, Kikuchi-Yanoshita R, Enomoto M, Igari T, Tanaka K, et al. Characteristics of somatic mutation of the adenomatous polyposis coli gene in colorectal tumors. Cancer Res. 1994;54:3011-20.
8. Bedi A, Pasricha PJ, Akhtar AJ, Barber JP, Bedi GC, Giardiello FM, et al. Inhibition of apoptosis during development of colorectal cancer. Cancer Res. 1995;55:1811-6.

9. Bei R, Masuelli L, Palumbo C, Modesti M, Modesti A. A common repertoire of autoantibodies is shared by cancer and autoimmune disease patients: Inflammation in their induction and impact on tumor growth. Cancer Lett. 2009;281:8-23.

10. Heo CK, Bahk YY, Cho EW. Tumor-associated autoantibodies as diagnostic and prognostic biomarkers. BMB Rep. 2012;45:677-85.

11. Zaenker P, Ziman MR. Serologic autoantibodies as diagnostic cancer biomarkers-a review. Cancer Epidemiol Biomarkers Prev. 2013;22:2161-81.

12. Toubi E, Shoenfeld Y. Protective autoimmunity in cancer (review). Oncology Rep. 2007;17:245-51.

13. Livingston PO, Ragupathi G, Musselli C. Autoimmune and antitumor consequences of antibodies against antigens shared by normal and malignant tissues. J Clin Immunol. 2000;20:85-93.

14. Merimsky O, Shoenfeld Y, Chaitchik S, Yecheskel G, Fishman P. Antigens and antibodies in malignant melanoma. Tumour Biol. 1994;15:188-202.

15. Madrid FF, Maroun MC. Serologic laboratory findings in malignancy. Rheum Dis Clin North Am. 2011;37:507-25.

16. Turriziani M, Fantini M, Benvenuto M, Izzi V, Masuelli L, Sacchetti $P$, et al. Carcinoembryonic antigen (CEA)-based cancer vaccines: recent patents and antitumor effects from experimental models to clinical trials. Recent Pat Anticancer Drug Discov. 2012;7:265-96.

17. Duffy MJ. Carcinoembryonic antigen as a marker for colorectal cancer: Is it clinically useful? Clin Chem. 2001;47:624-30.

18. Ganepola GA, Nizin J, Rutledge JR, Chang DH. Use of blood-based biomarkers for early diagnosis and surveillance of colorectal cancer. World J Gastrointest Oncol. 2014;6:83-97.

19. Griesenberg D, Nürnberg R, Bahlo M, Klapdor R. CEA, TPS, CA 19-9 and CA 72-4 and the fecal occult blood test in the preoperative diagnosis and follow-up after resective surgery of colorectal cancer. Anticancer Res. 1999;19:2443-50

20. Ausch C, Buxhofer-Ausch V, Olszewski U, Hamilton G. Circulating cytokeratin 18 fragments and activation of dormant tumor cells in bone marrow of cancer patients. Exp Ther Med. 2010;1:9-12.

21. Wang J, Hollingshead J, El-Masry N, Horncastle D, Talbot I, Tomlinson I, et al. Expression of EGFR, HER2, phosphorylated ERK and phosphorylated MEK in colonic neoplasms of familial adenomatous polyposis patients. J Gastrointest Cancer. 2012;43:444-55.

22. Roskoski Jr R. The ErbB/HER family of protein-tyrosine kinases and cancer Pharmacol Res. 2014;79:34-74.

23. Tchorzewski M, Boldyreff B, Issinger OG, Grankowski N. Analysis of the protein-protein interactions between the human acidic ribosomal $\mathrm{P}$ proteins: evaluation by the two hybrid system. Int J Biochem Cell Biol. 2000;32:737-46.

24. Naganuma T, Shiogama K, Schiumi T. The N-terminal regions of eukaryotic acidic phosphoproteins $\mathrm{P} 1$ and $\mathrm{P} 2$ are crucial for heterodimerization and assembly into the ribosomal GTPase-associated center. Genes Cells. 2007;12:501-10.

25. Remacha M, Jimenez-Diaz A, Santos C, Briones E, Zambrano R, Rodriguez Gabriel MA, et al. Proteins P1, P2, and P0, components of the eukaryotic ribosome stalk. New structural and functional aspects. Biochem Cell Biol. 1995;73:959-68.

26. Tchorzewski M, Boldyreff B, Grankowski N. Extraribosomal function of the acidic ribosomal P1-protein YP1alpha from Saccharomyces cerevisiae. Acta Biochim Pol. 1999:46:901-10.

27. Ito T, Chiba T, Ozawa R, Yoshida M, Hattori M, Sakaki Y. A comprehensive two-hybrid analysis to explore the yeast protein interactome. Proc Natl Acad Sci U S A. 2001:98:4569-74.

28. Bei R, Masuelli L, Trono P, Orvietani PL, Losito S, Marzocchella L, et al. The ribosomal P0 protein induces a spontaneous immune response in patients with head and neck advanced stage carcinoma that is not dependent on its overexpression in carcinomas. Int J Oncol. 2007;31:1301-8.

29. Marzocchella L, Sini V, Buonomo O, Orlandi A, Masuelli L, Bonanno E, et al. Spontaneous immunogenicity of ribosomal PO protein in patients with benign and malignant breast lesions and delay of mammary tumor growth in P0-vaccinated mice. Cancer Sci. 2011;102:509-15.

30. Ingrosso G, Fantini M, Nardi A, Benvenuto M, Sacchetti $P$, Masuelli L, et al. Local radiotherapy increases the level of autoantibodies to ribosomal P0 protein but not to heat shock proteins, extracellular matrix molecules and 
EGFR/ErbB2 receptors in prostate cancer patients. Oncol Rep. 2013;29:1167-74.

31. Elkon K, Skelly S, Parnassa A, Moller W, Danho W, Weissbach H, et al. Identification and chemical synthesis of a ribosomal protein antigenic determinant in systemic lupus erythematosus. Proc Natl Acad Sci U S A. 1986;83:7419-23

32. Mahler M, Kessenbrock K, Raats J, Williams R, Fritzler MJ, Blüthner M. Characterization of the human autoimmune response to the major $\mathrm{C}$ terminal epitope of the ribosomal P proteins. J Mol Med. 2003;81:194-204.

33. Koren E, Reichlin MW, Koscec M, Fugate RD, Reichlin M. Autoantibodies to the ribosomal P proteins react with a plasma membrane-related target on human cells. J Clin Invest. 1992;89:1236-41.

34. Chang TW, Chen CC, Chen KY, Su JH, Chang JH, Chang MC. Ribosomal phosphoprotein PO interacts with GCIP and overexpression of PO is associated with cellular proliferation in breast and liver carcinoma cells. Oncogene. 2008;27:332-8.

35. Bonfa E, Golombek SJ, Kaufman LD, Skelly S, Weissbach H, Brot N, et al. Association between lupus psychosis and anti-ribosomal P protein antibodies. N Engl J Med. 1987;317:265-71.

36. Barnard GF, Staniunas RJ, Bao S, Mafune K, Steele Jr GD, Gollan JL, et al. Increased expression of human ribosomal phosphoprotein PO messenger RNA in hepatocellular carcinoma and colon carcinoma. Cancer Res. 1992:52:3067-72.

37. Di Marco E, Pierce JH, Knicley CL, Di Fiore PP. Transformation of NIH 3 T3 cells by overexpression of the normal coding sequence of the rat neu gene. Mol Cell Biol. 1990;10:3247-52.

38. Bei R, Masuelli L, Moriconi E, Visco V, Moretti A, Kraus MH, et al. Immune responses to all ErbB family receptors detectable in serum of cancer patients. Oncogene. 1999;18:1267-75.

39. Bei R, Guptill V, Masuelli L, Kashmiri SV, Muraro R, Frati L, et al. The use of a cationic liposome formulation (DOTAP) mixed with a recombinant tumorassociated antigen to induce immune responses and protective immunity in mice. J Immunother. 1998;21:159-69.

40. Bradford MM. A rapid and sensitive method for the quantitation of microgram quantities of protein utilizing the principle of protein-dye binding. Anal Biochem. 1976;72:248-54.

41. Bei R, Moretti A, Visco V, De Filippi R, Tsang KY, Frati L, et al. Cell mediated cytotoxicity of human colon carcinoma cells by a monoclonal antibody (R4) recognizing the carcinoembryonic antigen (CEA) and CEA-related molecules. Int J Oncol. 1996;8:1127-35.

42. Bei R, Romano M, Caputo MP, Sconocchia G, Capuani B, Coppola A, et al. A survey of autoantibodies to self antigens in Graves' disease patients with thyroid associated ophthalmopathy. Eur I Inflammation. 2013;11:539-46.

43. Masuelli L, Di Stefano E, Fantini M, Mattera R, Benvenuto M, Marzocchella L, et al. Resveratrol potentiates the in vitro and in vivo anti-tumoral effects of curcumin in head and neck carcinomas. Oncotarget. 2014;5:10745-62.

44. Orlandi A, Costantini S, Campione E, Ferlosio A, Amantea A, Bianchi L, et al. Relation between animal-type melanoma and reduced nuclear expression of glutathione S-transferase pi. Arch Dermatol. 2009;145:55-62.

45. Bei R, Pompa G, Vitolo D, Moriconi E, Ciocci L, Quaranta M, et al. Colocalization of multiple ErbB receptors in stratified epithelium of oral squamous cell carcinoma. J Pathol. 2001;195:343-8.

46. Orlandi A, Ciucci A, Ferlosio A, Pellegrino A, Chiariello L, Spagnoli LG. Increased expression and activity of matrix metalloproteinases characterize embolic cardiac myxomas. Am J Pathol. 2005;195:1619-28.

47. Stasi MA, Scioli MG, Arcuri G, Mattera GG, Lombardo K, Marcellini M, et al. Propionyl-L-carnitine improves postischemic blood flow recovery and arteriogenetic revascularization and reduces endothelial NADPH-oxidase 4-mediated superoxide production. Arterioscler Thromb Vasc Biol. 2010;30:426-35

48. Masuelli L, Budillon A, Marzocchella L, Mrozek MA, Vitolo D, Di Gennaro E, et al. Caveolin-1 overexpression is associated with simultaneous abnormal expression of the E-cadherin/ $\mathrm{a}-\mathrm{B}$ catenins complex and multiple ErbB receptors and with lymph nodes metastasis in head and neck squamous cell carcinomas. J Cell Physiol. 2012;227:3344-53.

49. Masuelli L, Benvenuto M, Fantini M, Marzocchella L, Sacchetti P, Di Stefano $E$, et al. Curcumin induces apoptosis in breast cancer cell lines and delays the growth of mammary tumors in neu transgenic mice. J Biol Regul Homeost Agents. 2013;27:105-19.

50. Masuelli L, Fantini M, Benvenuto M, Sacchetti P, Giganti MG, Tresoldi I, et al. Intratumoral delivery of recombinant vaccinia virus encoding for ErbB2/Neu inhibits the growth of salivary gland carcinoma cells. J Transl Med. 2014;12:122

51. Masuelli L, Marzocchella L, Quaranta A, Palumbo C, Pompa G, Izzi V, et al. Apigenin induces apoptosis and impairs head and neck carcinomas EGFR/ ErbB2 signaling. Front Biosci (Landmark Ed). 2011;16:1060-8.

52. Miles AK, Matharoo-Ball B, Li G, Ahmad M, Rees RC. The identification of human tumour antigens: current status and future developments. Cancer Immunol Immunother. 2006;55:996-1003.

53. Waldner M, Schimanski CC, Neurath MF. Colon cancer and the immune system: the role of tumor invading T cells. World J Gastroenterol. 2006;12:7233-8.

54. Lech G, Slotwinski R, Krasnodebski IW. The role of tumor markers and biomarkers in colorectal cancer. Neoplasma. 2014;61:1-8.

55. Barderas R, Villar-Vázquez R, Fernández-Aceñero MJ, Babel I, Peláez-García A, Torres $S$, et al. Sporadic colon cancer murine models demonstrate the value of autoantibody detection for preclinical cancer diagnosis. Sci Rep. 2013;3:2938

56. Zhang JY, Zhu W, Imai H, Kiyosawa K, Chan EK, Tan EM. De-novo humoral immune responses to cancer-associated autoantigens during transition from chronic liver disease to hepatocellular carcinoma. Clin Exp Immunol. 2001:125:3-9.

57. Toubi E, Shoenfeld Y. Clinical and biological aspects of anti-P-ribosomal protein autoantibodies. Autoimmun Rev. 2007;6:119-25.

58. Teh LS, Lee MK, Wang F, Manivasagar M, Charles PJ, Nicholson GD, et al. Antiribosomal P protein antibodies in different populations of patients with systemic lupus erythematosus. Br J Rheumatol. 1993;32:663-5.

59. Artero-Castro A, Castellvi J, García A, Hernández J, Ramóny Cajal S, Lleonart ME. Expression of the ribosomal proteins Rplp0, Rplp1, and Rplp2 in gynecologic tumors. Hum Pathol. 2011;42:194-203.

60. Vacchelli E, Aranda F, Eggermont A, Galon J, Sautès-Fridman C, Zitvogel L, et al. Trial Watch: Tumor-targeting monoclonal antibodies in cancer therapy. Oncoimmunology. 2014;3:e27048

61. Ackerman D, Simon MC. Hypoxia, lipids, and cancer: surviving the harsh tumor microenvironment. Trends Cell Biol. 2014;24:472-8.

62. Sun KH, Tang SJ, Lin ML, Wang YS, Sun GH, Liu WT. Monoclonal antibodies against human ribosomal $P$ proteins penetrate into living cells and cause apoptosis of Jurkat T cells in culture. Rheumatology (Oxford). 2001:40:750-6.

63. Koscec M, Koren E, Wolfson-Reichlin M, Fugate RD, Trieu E, Targoff IN, et al. Autoantibodies to ribosomal P proteins penetrate into live hepatocytes and cause cellular dysfunction in culture. J Immunol. 1997;159:2033-41.

64. Reichlin M. Cellular dysfunction induced by penetration of autoantibodies into living cells: cellular damage and dysfunction mediated by antibodies to dsDNA and ribosomal P proteins. J Autoimmun. 1998;11:557-61.

\section{Submit your next manuscript to BioMed Central and take full advantage of:}

- Convenient online submission

- Thorough peer review

- No space constraints or color figure charges

- Immediate publication on acceptance

- Inclusion in PubMed, CAS, Scopus and Google Scholar

- Research which is freely available for redistribution 